\title{
Cystoseira Barbata İle Toryum Biyosorpsiyonu
}

\section{Biosorption of radioactive thorium by Cystoseira barbata Yeliz Özüdoğru*}

\author{
*Çanakkale Onsekiz Mart Üniversitesi, Eğitim Fakültesi, Kimya Eğitimi Anabilim Dalı, Çanakkale \\ Sorumlu Yazar / Corresponding Author *: yelizozudogru@hotmail.com \\ Geliş Tarihi /Received: 05.11.2018 DOI:10.21205/deufmd.2019216212 \\ Kabul Tarihi / Accepted: 13.12.2018 Araștırma Makalesi/Research Article \\ Atıfsekli/How to cite: ÖZÜDOĞRU, Y. (2019). Cystoseira Barbata Ile Toryum Biyosorpsiyonu. DEUFMD, 21(62), 461-468.
}

Öz

Bu çalışmada, Cystoseira barbata'nın biyosorbent olarak kullanılmasıyla, sulu çözeltide bulunan Th (IV) radyoaktif iyonlarının giderilmesine çalışılmıştır. Kesikli ekstraksiyon yöntemi uygulanmış ve biyosorpsiyona $\mathrm{pH}$, süre ve derişim gibi etkileri incelenmiştir. Tutunma miktarının $\mathrm{pH}$ değișiminden pek etkilenmediği belirlenmiştir. Süre denemeleri sonucunda ise, biyosorpsiyon işleminin ilk 150 dakika içerisinde dengeye ulaștığı görülmüștür. Derișim denemeleri sonucunda elde edilen verilere, Langmuir ve Freundlich izoterm modelleri uygulanmış, qm değeri 39,45 mg/g olarak bulunmuştur. Adsorpsiyon denemeleri sonucunda, adsorpsiyonun Freundlich izoterm modeline daha çok uyduğu belirlenmiștir. Yapılan SEM (Scanning Electron Microscop) ve FTIR (Fourier transformed-infrared spectroscopy) analizleri ile radyoaktif maddenin alg yüzeyinde meydana getirdiği değişiklikler gözlenmiș ve Th (IV) radyoaktif iyonlarının alg yüzeyinde hangi gruplara tutunduğu belirlenmiștir. Anahtar Kelimeler: Cystoseira barbata, Th, biyosorpsiyon.

\section{Abstract}

In this study, it was tried to remove Th (IV) radioactive ions in aqueous solution by using Cystoseira barbata. Batch extraction method was applied and $\mathrm{pH}$, contact time and concentration effects were investigated. It was determined that the amount of removal was not affected by $\mathrm{pH}$ change. As a result of time effects, it was observed that the biosorption process reached equilibrium with in the first 150 minutes. Langmuir and Freundlich isotherm models were applied and qm value was found to be $39,45 \mathrm{mg} / \mathrm{g}$. The Freundlich isotherm model showed slightly stronger correlation than Langmuir isotherm. SEM and FTIR analysis were performed to find out the changes on the surface of algae loaded with Th (IV) radioactive ions and the groups Th (IV) attached on algae surface.

Keywords: Cystoseira barbata, Th, biosorption.

\section{Giriş}

En çok üzerinde durulan çevre kirliliği kaynaklarından birisi de ağır metal kirliliğidir. Radyoaktif atıklar tıp, metal yüzey kaplama, endüstri, araștırma- uygulama, madencilik ve yakıt uygulamaları sonucunda ortaya çıkabilmektedir. $\mathrm{Bu}$ atıklar çevreye yayılarak yeraltı sularını ve dolayısı ile de insan sağlığını ciddi boyutlarda tehdit etmektedir [1]. Bu maddelerin diğer atıklardan daha farklı bir şekilde ortamdan uzaklaştırılması için çeşitli fiziksel ve kimyasal arıtım teknikleri ve yöntemleri kullanılmaktadır [2-5]. Radyoaktif maddelerin arıtımı için iyon değiştirme, kimyasal oksidasyon ya da redüksiyon, ters ozmoz, mebran ayırma gibi teknikler kullanılmakla birlikte [4-6], bu tekniklerde bazı problemler yaşanmaktadır. Mesela kimyasal 
çöktürme, sulu çözeltide bulunan metal iyonları 1 ile $100 \mathrm{mg} / \mathrm{L}$ arasında olduğunda pek efektif bir metot değildir. Diğer yandan, iyon değişimi, mebran teknolojisi ve aktif karbon adsorpsiyon prosesi oldukça pahalı bir yöntemdir $[7,8]$. Atık sulardan ağır metallerin giderimi konusunda bulunması kolay, etkili, ekonomik ve çevreye duyarlı tekniklerin geliştirilmesi önem arz etmektedir [9]. Bu nedenle, biyosorbsiyon yöntemi, daha efektif, daha ucuz, çevreye daha az zarar veren ve dolayısı ile daha avantajlı olması nedeni ile son yılarda tercih edilmektedir [10-12].

Biyosorbsiyon yönteminde bașta algler olmak üzere bakteri ve mantarlar kullanılmaktadır $[13,14]$. Alglerin, polisakkarit, amino, hidroksil, karboksil ve sülfat gibi fonksiyonel gruplara sahip olmaları nedeni ile ağır metalleri tutma kapasiteleri oldukça yüksektir $[15,16]$. Kahverengi algler kuru ağırlıklarının \%20'si ile $\%$ 40'ı arasında aljinik asit içermekte ve bu nedenle de alglerin metal iyonlarını tutma kapasiteleri daha yüksek olmaktadır $[17,18]$.

Biyosorbsiyon yönteminde alg kullanılarak radyoaktif metal giderimi yapılan pek çok çalıșmalar bulunmaktadır $[4,9,19] . \mathrm{Bu}$ çalışmalarda kesikli ekstraksiyon yöntemi uygulanmıș ve denemelerde, pH, sicaklık, derişim gibi faktörlerin etkileri incelenmiştir. Atık sularda bulunan Th (IV) iyonlarının alg kullanarak giderilmesine yönelik de pek çok çalışma bulunmaktadır [20-24].

Toryum (Th), hem çevresel etkilerinden dolayı, hem de endüstriyel uygulamaları açısından, en tehlikeli ağır metallerden birisidir [1,25]. Th, nükleer yakıt olarak, bileşikleri ise kimyada, endüstride, seramik üretiminde, yüksek kalitedeki lens üretiminde ve maden işletmeciliğinde kullanılmaktadır $[19,26]$.

Bu çalıșmanın amacı, çevre ve insan sağlığı için oldukça tehlikeli olan Th (IV) radyoaktif elementinin, daha önceden denenmemiş bir alg türü olan Cystoseira barbata kullanarak sucul ortamdan giderimini sağlamaktır.

\section{Materyal ve Metot}

\subsection{Biyokütle olarak C. barbata'nın hazırlanması}

Esmer alglerden olan C. barbata (Stackhouse) C. Agardh, Canakkale Onsekiz Mart Üniversitesi'nin Dardanos Kampüsünden toplanmıștır. Biyomas, temizlenmiș, yıkanmıș ve $60^{\circ} \mathrm{C}$ 'de etüvde kurutulmuştur.

\subsection{Kullanılan kimyasallar ve cihazlar}

Kullanılan tüm kimyasallar, analitik hassasiyette olup, Merck firmasından temin edilmiștir. Denemelerde kullanılan tüm çözeltiler saf su ile hazırlanmıștır. Biyosorbisyon denemeleri için, stok Th(IV) çözeltisi $\mathrm{Th}\left(\mathrm{NO}_{3}\right)_{4}$ bileşiği kullanılarak 1000 ppm olacak şekilde hazırlanmıştır. Çözeltilerin pH ayarlanması için $0,1 \mathrm{M} \mathrm{HCl}$ ve $0,1 \mathrm{M} \mathrm{NaOH}$ kullanılmıştır. Biyosorpsiyon denemelerinde Wise Bath WSB-30 model sicaklık ayarlamalı çalkalayıcılı su banyosu kullanılmıștır. Biyosorpsiyon denemeleri sonucunda örnekler, Millipore Millex-HV hydrophilic PVDF 0,45 $\mu \mathrm{m}$ şırınga filtre ile süzülmüştür. Süzülen örneklerdeki Th(IV) iyon derişimini bulabilmek için, örneklerden 3ml alınıp, 0,2 ml Arsenozo (III) çözeltisi ve $1 \mathrm{ml} 1 \mathrm{M}$ HNO3 çözeltisi ilave edilmiş ve 5 ml'ye tamamlanmıştır. Ölçüm öncesinde hem kör çözeltisinin, hem de Th(IV) çözeltisinin dalga boyu taraması yapılmış (Şekil 1), örneklerdeki Th(IV) radyoaktif madde miktarı Rayleigh Vis-7220G spektrofotometre ile 667 nm.'de ölçülmüştür. Örneklerin karakterizasyonda, Fourier transformedinfrared spectroscopy (FTIR) için, Perkin-Elmer FTIR Spectrometre (Spectrum BX-II) ve Scanning Electron Microscope (SEM, Jeol JSM 7100F) cihazları kullanılmıştır.

\subsection{Biyosorpsiyon denemeleri}

Biyosorpsiyon yöntemi olarak kesikli ekstraksiyon yöntemi kullanılmıștır. $100 \mathrm{mg} C$. barbata 50 mL'lik falkon tüplerine konularak 10 mL'lik Th(IV) çözeltisi ilave edilmiştir. Hazırlanan örneklerin farklı pH'larda, farklı sürelerde ve farklı derișimlerde denemeleri yapılmıștır. Örnekler, 250 rpm hızındaki çalkalamalı su banyosunda ve üç tekrarlı olacak şekilde çalkalanmış, şırınga filtre ile süzülerek spektrofotometrede okunmuștur. 
DEU FMD 21(62), 461-468, 2019

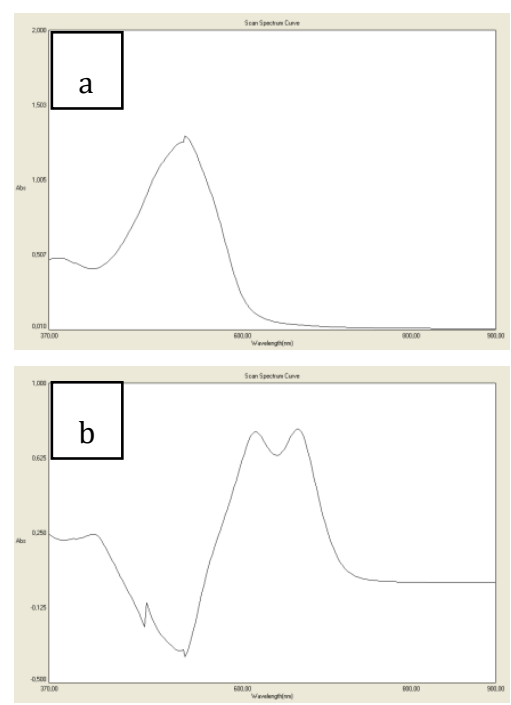

Şekil 1. Kör (a) ve Th(IV) (b) çözeltisinin dalga boyu taraması

\section{4. pH denemeleri}

pH denemeleri için $100 \mathrm{mg}$ C. barbata'ya farklı pH'larda (2-3-5-7-9) bulunan 10 ppm'lik $10 \mathrm{ml}$. Th(IV) çözeltileri ilave edilerek 50 ml'lik falkon tüplerine konulmuştur. Sıcaklık ayarlı çalkalamalı su banyosunda 1 saat süre ile 250 rpm hızında ve oda koşullarında çalkalanmıștır. Örnekler süzülmüș adsorbe edilen Th(IV) miktarının hesaplanabilmesi için spektrofotometrede okunmuştur.

pH'a bağlı \% Tutunma kapasitesi Eşitlik (1)'e göre hesaplanmıştır.

\%Tutunma $=\frac{C_{o}-C_{e}}{C_{o}} * 100$

Denklemdeki $C_{o}$ değeri başlangıç radyoaktif madde derişimini $(\mathrm{mg} / \mathrm{L}), C_{e}$ ise dengedeki radyoaktif madde derişimini (mg/L) vermektedir.

\subsection{Süre Denemeleri}

C. barbata'nın süre denemeleri için, $100 \mathrm{mg}$ biyokütle falkon tüplerinde bulunan $10 \mathrm{~mL}$ 'lik Th(IV) çözeltilerine ilave edilmiștir. Çalkalamalı su banyosunda $250 \mathrm{rpm}$ hızında farklı sürelerde (10-25-50-100-150-200 ve 300 dk) çalkalanmıştır. Süreye bağlı qt değerleri Eşitlik (2)'ye göre hesaplanmıştır.
$\mathrm{qt}=\frac{\left(C_{\mathrm{o}}-C_{e}\right)}{M} * \mathrm{v}$

Denklemdeki $\mathrm{q}_{\mathrm{t}}$ değeri, adsorblanan radyoaktif madde miktarını (mg/g), $C_{o}$ ve $C_{e}$ sırasıyla başlangıç ve dengedeki radyoaktif madde derișimini (mg/L), $\mathrm{V}$ çözelti hacmini (L), $M$ ise biyosorbentin kütlesini (g) göstermektedir.

\subsection{Adsorpsiyon izotermleri}

Farklı derișimlerde (5-10-20-50-100-150-200$300-350-400-450$ ve $500 \mathrm{mg} / \mathrm{L}$ ) bulunan 10 ml.lik radyoaktif madde çözeltileri $100 \mathrm{mg} C$. barbata'ya ilave edilmiş, $150 \mathrm{dk}$ süre ile çalkalanmıştır.

Adsorbent yüzeyinde oluşan adsorpsiyon olayı, Langmuir ve Freundlich izoterm modelleri ile açıklanmıştır. Langmuir izoterm modeli Eşitlik (3)' de gösterilmiștir [27].

$\frac{C_{e}}{q_{e}}=\frac{1}{q_{m} a_{L}}+\frac{C_{e}}{q_{m}}$

Burada $q_{e}$, adsorplanan radyoaktif madde miktarını (mg/g), $C_{e}$ dengedeki çözeltide adsorplanmadan kalan radyoaktif madde derişimini (mg/L), $q_{m}$ maksimum adsorbsiyon kapasitesini ve $a_{L}$ de adsorbsiyon enerjisi ile ilgili Langmuir sabitini göstermektedir. Lineer regresyon analizine göre $C_{e} / q_{e}$ değerinin $C_{e}$ değerine karşı çizilen grafikteki doğrunun eğimi $1 / q_{m}$ değerini, doğrunun kesim noktası ise $1 /$ $q_{m} a_{L}$ değerini vermektedir.

Çok tabakalı adsorbsiyon modelinden üretilerek heterojen yüzeyler için uygulanan Freundlich izoterm modeli Eşitlik (4)'de gösterilmiştir [28].

$q_{e}=K_{f} C e^{1 / n f}$

Burada, $q_{e}$ denge anında biyokütle üzerine adsorplanan radyoaktif madde miktarını $(\mathrm{mg} / \mathrm{g}), K_{f}$ adsorbsiyon kapasitesini $(\mathrm{mg} / \mathrm{g}), n_{f}$ Freundlich izoterm sabitini, $C_{e}$ denge halinde çözeltide kalan radyoaktif madde konsantrasyonunu $(\mathrm{mg} / \mathrm{L})$ ifade etmektedir.

Eşitlik (4)'de her iki tarafın logaritmasının alınması ile lineer hale gelen yeni denklem Eşitlik (5)'de gösterilmiştir.

$\log q_{e}=\log K_{f}+1 / n_{f} \log C_{e}$ 
$\mathrm{Bu}$ eșitlikte, $\log q_{e}$ değerlerine karșı çizilen log $C_{e}$ değerlerinin olușturduğu grafikteki doğrunun eğimi $1 / n_{f}$ değerini ve doğrunun y eksenini kestiği nokta da $\log K_{f}$ değerini vermektedir. 1/ $n_{f}$ değeri sıfıra ne kadar yakınsa yüzey o kadar heterojen demektir.

\subsection{Biyomasın karakterizasyonu}

FTIR analizi için, C. barbata $60^{\circ}$ C'de ağırlığı sabit kalıncaya kadar etüvde kurutulmuş, $1 \mathrm{mg}$ biyomas, $100 \mathrm{mg} \mathrm{KBr}$ ile pelet haline getirilmiștir. Biyomasın karakterizasyonda aralık olarak 400-4000 cm-1 kullanılmıștır. Radyoaktif maddenin adsorpsiyon öncesi ve sonrası alg yüzeyinde meydana gelen değişiklikleri gözlemleyebilmek için voltaj aralığı 5-7 kV ayarlanmıș Scanning Electron Microscop (SEM, Jeol JSM 7100F) kullanılmıştır. Analiz öncesi, örnekler kurutularak altın ile kaplanmıştır.

\section{Bulgular}

\section{1. pH denemeleri}

Biyosorpsiyon denemelerinde en önemli faktörlerden birisi pH'dır. Çünkü, biyokütledeki fonksiyonel grupların aktivitesini ve adsorbe edilecek iyonların çözeltideki aktivitesine etki etmektedir [29].

Biyosorpsiyona pH'ın etkisinin incelenmesi için, $100 \mathrm{mg}$ C. barbata'ya farklı $\mathrm{pH}^{\prime}$ larda (2-3-5-7-9) bulunan 10 ppm'lik $10 \mathrm{ml}$. Th(IV) çözeltileri ilave edilmiştir. Ölçüm sonucu elde edilen veriler Şekil 2'de gösterilmiştir. Elde edilen verilere göre, $\mathrm{pH}$ 3'den sonra Th(IV) iyonunun \% tutunma kapasitesi artmıștır. Yapılan diğer çalışmalarla elde edilen veriler uygunluk göstermektedir [28, 30].

\subsection{Süre denemeleri}

Radyoaktif iyonların adsorbsiyonunda, adsorpsiyon süresi de oldukça önemlidir. Kullanılan biyokütleye ve radyoaktif iyona ya da metala bağlı olarak biyosorpsiyon süresi değișmekle birlikte, genel anlamda bakıldığında ortalama olarak 2 saat içerisinde reaksiyonun dengeye geldiği belirtilmektedir [12].

Süre denemeleri için, hazırlanan örnekler, farklı sürelerde (10-25-50-100-150-200 ve $300 \mathrm{dk}$ ) çalkalamalı su banyosunda $250 \mathrm{rpm}$ hızında çalkalanmış, q $\mathrm{q}_{\mathrm{t}}$ değerleri hesaplanmıştır. Elde edilen veriler Șekil 3'de gösterilmiștir. Sürenin artması ile birlikte, $\mathrm{q}_{\mathrm{t}}$ değerlerinin de azaldığ görülmüștür. İlk 50 dakika içerisinde adsorplanan iyon derişiminin ( $\mathrm{q}_{\mathrm{t}}$ değeri 0,13 -
$0,12 \mathrm{mg} / \mathrm{g}$ ) en fazla olduğu, zamanın artmasıyla birlikte azaldığı belirlenmiștir.

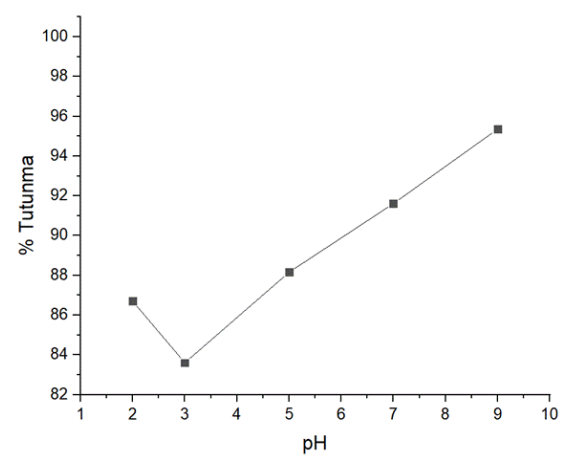

Şekil 2. C. barbata'nın pH'a bağlı \% tutunma grafiği

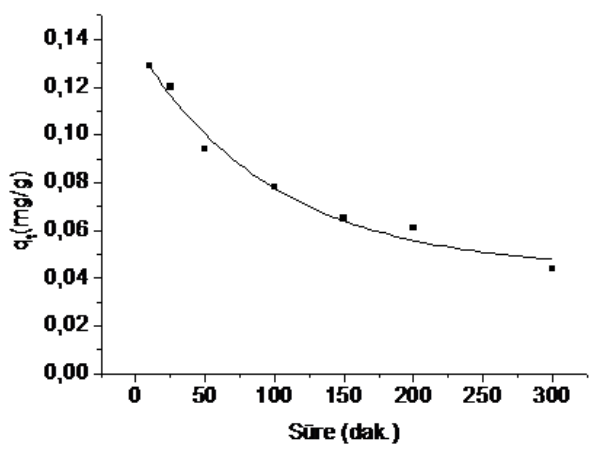

Şekil 3. C. barbata'nın süreye bağlı $\mathrm{q}_{t}$ değerleri

\subsection{Adsorpsiyon izotermleri}

Biyosorpsiyon yöntemi, radyoaktif iyonlar için hızlı ve geri dönüşümlü bir prosestir [31]. Adsorpsiyon çalışmaları ile çeşitli modeller yapılarak, radyoaktif iyonların biyokütleye nasıl tutunduğu anlaşlabilmektedir. Farklı derișimlerde (5-10-20-50-100-150-200-300350- $400-450$ ve $500 \mathrm{mg} / \mathrm{L}$ ) bulunan Th(IV) radyoaktif çözeltileri oda koşullarında $150 \mathrm{dk}$ süre ile çalkalanmıştır. Elde edilen verilere Langmuir ve Freundlich izoterm modelleri uygulanmıștır. Elde edilen sonuçlar Tablo 1'de gösterilmiștir.

Tablo 1'e göre, Freundlich izoterm modelinin $\left(\mathrm{R}_{\mathrm{f}}{ }^{2}=0,9627\right)$ Langmuir izoterm modeline göre $\left(\mathrm{R}_{\mathrm{L}}{ }^{2}=0,9425\right)$ daha çok uyduğu belirlenmiştir. C. barbata'nın Th(IV) iyonunu maksimum adsorplama kapasitesinin ise $\left(\mathrm{q}_{\max }\right.$ ) 39,45 $\mathrm{mg} / \mathrm{g}$ olduğu hesaplanmıștır. C. barbata için hesaplanan qmax değeri ile farklı biyokütlelerin 
DEU FMD 21(62), 461-468, 2019

qmax değerlerinin karşılaștırılması Tablo 2'de verilmiştir.

Tablo 1. C. barbata'da Th (IV) için Langmuir ve Freundlich izoterm sabitleri ve regresyon katsayıları $\left(\mathrm{R}^{2}\right)$

\begin{tabular}{llllll}
\hline \multicolumn{2}{l}{ Langmuir izoterm modeli } & \multicolumn{4}{c}{ Freundlich izoterm modeli } \\
\hline $\begin{array}{l}q_{m} \\
(\mathrm{mg} / \mathrm{g})\end{array}$ & $a_{L}$ & $R_{L}{ }^{2}$ & $n_{f}$ & $\begin{array}{l}K_{f} \\
(\mathrm{mg} / \mathrm{g})\end{array}$ & $R_{F}{ }^{2}$ \\
39,45 & 21,99 & 0,9425 & 0,64 & 3,085 & 0,9627 \\
\hline
\end{tabular}

Tablo 2. Th (IV) iyonunun farklı biyosorbentle biyosorpsiyon kapasiteleri

\begin{tabular}{|c|c|c|c|}
\hline Biyokütle & $\begin{array}{l}\text { Radyoaktif } \\
\text { iyon }\end{array}$ & $\begin{array}{l}\mathrm{q}_{\max } \\
(\mathrm{mg} / \mathrm{g})\end{array}$ & Referans \\
\hline R. arrhizus & $\mathrm{Th}$ & 238,1 & {$[32]$} \\
\hline Cystoseira indica & Th & 169,49 & {$[26]$} \\
\hline Aspergillus niger & Th & 22 & [33] \\
\hline $\begin{array}{l}\text { Cystoseira indica } \\
\left(\mathrm{CaCl}_{2} \text { ile }\right. \\
\text { görmüsş })\end{array}$ & $\mathrm{Th}$ & 195,7 & {$[34]$} \\
\hline Ulva gigantea & $\mathrm{Th}$ & 2,728 & [3] \\
\hline Cystoseira barbata & $\mathrm{Th}$ & 21,99 & $\begin{array}{l}\text { Bu } \\
\text { çalıșma }\end{array}$ \\
\hline
\end{tabular}

\subsection{Biyomasın karakterizasyonu}

\subsubsection{FTIR analizi}

FTIR analizleri, alg yüzeyinde meydana gelen adsorplama olayının tanımlanmasinda kullanılır. Algler içerdikleri protein, vitamin, polisakkarit ve yağ asitlerinden dolayı, hidroksil, karboksil, amino, fosfat, amin gibi fonksiyonel gruplara sahiptirler $[11,35,36]$. $C$. barbata'nın Th(IV) iyonunun yüklenmeden ve yüklendikten sonraki FTIR analizi Şekil 4'de ve fonksiyonel gruplarının değişimi ise Tablo 3'de verilmiștir. $3428 \mathrm{~cm}-1$ 'deki pikin $3276 \mathrm{~cm}-1$ 'e kaydığı görülmüștür. 2933 cm-1, 1654 cm-1, $1635 \mathrm{~cm}-1$ deki piklerin ise kaybolduğu görülmüştür. Genel anlamda bakıldığında, $C$. barbata'ya Th(IV) iyonunun bağlanması bazı piklerde kaymalara neden olurken, bazı piklerin de kaybolmasını sağlamıştır.

\subsubsection{SEM analizi}

Denemelerde kullanılan algin yüzey yapısının anlaşılması için SEM/EDX analizleri yapılmıștır. C. barbata'ya Th (IV) iyonu (Şekil 5) yüklendikten sonra meydana gelen yüzey değişimi araştırılmıştır. Th (IV) iyonu yüklemesinde, yüzey değişerek katmanlı ve tabakalı bir yapıya benzemiştir. Yapılan EDX analizinde ise, yüklenen Th (IV) iyonunun varlığı tespit edilmiştir.
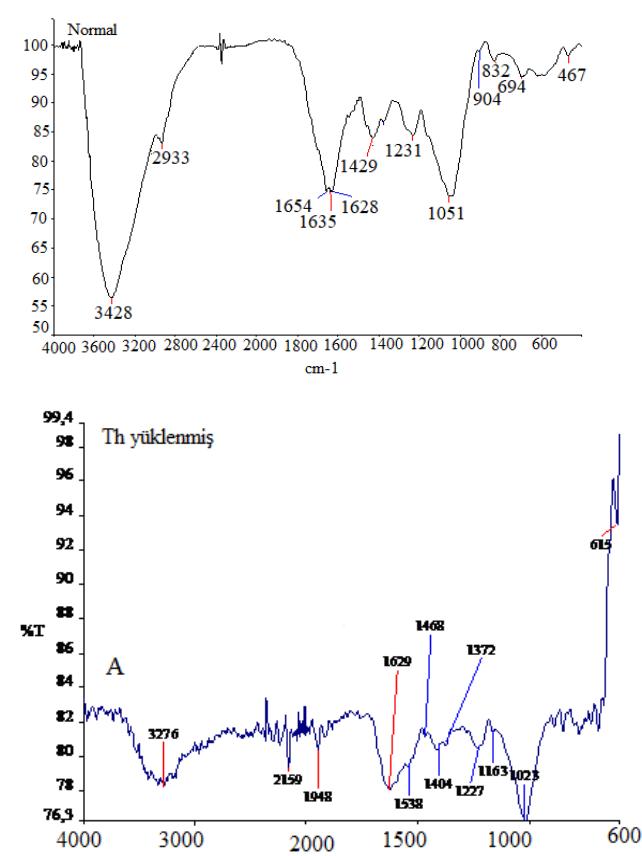

Şekil 4. C. barbata'nın FTIR analizi (Normal ve Th (IV) iyonu yüklenmiş hali) 
DEU FMD 21(62), 461-468, 2019

Tablo 3. C. barbata'nın FTIR analizi sonucunda fonksiyonel grupları.

\begin{tabular}{lc}
\hline Fonksiyonel gruplar & C. barbata \\
\hline -OH ve - NH gerilme & 3428 \\
-CH gerilme & 2933 \\
C = O grup (Amid) & 1654 \\
C-O gerilme & 1429 \\
C-O karboksil & 1231 \\
S=0 gerilme & 1051 \\
S-O gerilme & 832 \\
\hline
\end{tabular}

\section{Tartışma ve Sonuç}

Bu çalıșma kapsamında, esmer alglerden olan $C$. barbata'da Th (IV) radyoaktif iyonunun adsorplama özelliği incelenmiştir. Bu bağlamda, $\mathrm{pH}$, süre, radyoaktif iyonun derişim özellikleri gibi faktörlerin adsorpsiyon üzerindeki etkileri incelenmiștir. Elde edilen sonuçlar, FTIR, SEM ve EDX analizleri ile desteklenmiştir.

Yapılan analizlerden $\mathrm{pH}$ değişiminin etkisi incelendiğinde, Th(IV) iyonunun tutunma miktarının pH 3'den sonra artarak \% 95 seviyesine ulaştığı belirlenmiştir. Adsorpsiyona süre değişimin etkisi incelendiğinde ise, ilk anda hızlı bir șekilde adsorplama olayının gerçekleştiği, sürenin artması ile birlikte, kullanılan algin doygunluğa ulaşarak, adsorplama kapasitesinin azaldığı görülmüștür. Yapılan izoterm çalışmalarında ise, Th(IV) iyonunun adsorplanma olayının Freundlich izoterm modeline daha çok uyduğu ve elde edilen qmax değerinin ise, $36,45 \mathrm{mg} / \mathrm{g}$ olduğu belirlenmiștir. Yapılan FTIR analizlerinde, radyoaktif iyonlar, alg çeperinde bulunan $-\mathrm{OH}$, $\mathrm{NH},-\mathrm{CH},-\mathrm{C}=\mathrm{O}$ gruplarına bağlanmıștır. SEM analizlerinde ise, radyoaktif iyonların biyomasa etkileri net bir şekilde gözlenmiş ve yapılan EDX analizleri ile de radyoaktif iyonların varlığı tespit edilmiştir.

Sonuç olarak, radyoaktif olan Th(IV) iyonlarının gideriminde esmer alglerden olan C. barbata'nın kullanılabilirliği belirlenmiştir.

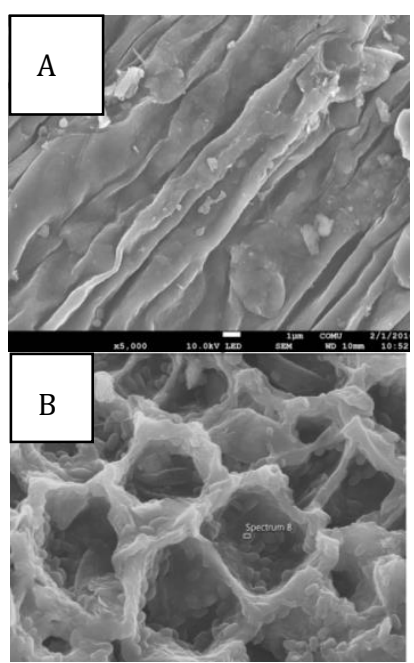

Şekil 5. C. barbata'nın saf ve Th(IV) iyonu yüklenmiş SEM (A: C. barbata, B: C. barbata + Th(IV) iyonu yüklenmiş) analizi

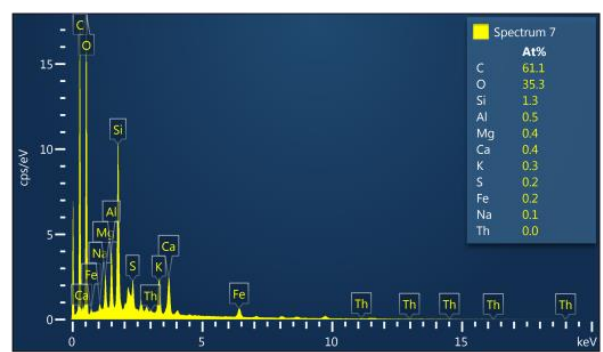

Şekil 6. C. barbata'nın EDX analizi

\section{Teşekkür}

Hazırlanan bu çalıșma, Çanakkale Onsekiz Mart Üniversitesi Bilimsel Araştırma Projeleri Komisyonu tarafından FBA-2016-968 no'lu proje ile desteklenmiştir. Çalışmada yardımcı olan Melek MERDIVAN'a ve Tolga GÖKSAN'a teşekkür ederim. 


\section{Kaynakça}

[1] Moghaddam, M.R., Fatemi,S. ve Keshtkar A. 2013. Adsorption of lead $\left(\mathrm{Pb}^{2+}\right)$ and uranium $\left(\mathrm{UO}_{2}{ }^{2+}\right)$ cations by brown algae; experimental and thermodynamic modeling. Chemical Engineering Journal, cilt 231, s. 294-303. https://doi.org/10.1016/j.cej.2013.07.037

[2] Ünak, P., Radyoaktif atıkların Yönetimi. http://euatik.ege.edu.tr/files/radyoaktifatiklarinyo netimi.pdf, 2011.

[3] Bozkurt, S., Molu, Z., Cavas, L., ve Merdivan, M. 2011. Biosorption of uranium (VI) and thorium (IV) onto Ulva gigantea (Kützing) bliding: discussion of adsorption isotherms, kinetics and thermodynamic Journal of Radioanalytical and Nuclear Chemistry, cilt 288(3), s. 867-874

[4] Keshtkar, A.R., Mohammadi, M., ve Moosavian, M.A 2015. Equilibrium biosorption studies of wastewater U(VI), $\mathrm{Cu}(\mathrm{II})$ and $\mathrm{Ni}(\mathrm{II})$ by the brown alga Cystoseira indica in single, binary and ternary metal systems. Journal of Radioanalytical and Nuclear Chemistry, cilt 303(1), s. 363-376.

[5] Aytas, S., Gunduz, E. ve Gok, C. 2014. Biosorption of Uranium Ions by Marine Macroalga Padina pavonia. CLEAN - Soil, Air, Water, cilt 42(4), s. 498-506.

[6] Altunyaldız, A., Başlak, C., Arslan, G. 2018. CdSe Nanokristalleri ile Mikrokapsül Hazırlama ve Cr(VI) Gideriminde Kullanılması. Dokuz Eylül ÜniversitesiMühendislik Fakültesi, cilt 20(60), s. 711-724

[7] Wang, J. ve Chen, C. 2009. Biosorbents for heavy metals removal and their future. Biotechnology Advances, cilt 27(2), s. 195-226 https://doi.org/10.1016/j.biotechadv.2008.11.002

[8] Farooq, U., Kozinski, J.A., Khan, M.A. ve Athar, M. 2010. Biosorption of heavy metal ions using whea based biosorbents - A review of the recent literature. Bioresource Technology, cilt 101(14), s. 5043-5053.

https://doi.org/10.1016/j.biortech.2010.02.030

[9] Ghasemi, M., Keshtkar, A.R., Dabbagh, R. ve Safdari S.J. 2011. Biosorption of uranium(VI) from aqueous solutions by Ca-pretreated Cystoseira indica alga: Breakthrough curves studies and modeling. Journal of Hazardous Materials, cilt 189(1), s. 141-149. doi.org/10.1016/j.jhazmat.2011.02.011

[10] Kratochvil, D. ve Volesky, B. 1998. Advances in the biosorption of heavy metals. Trends in Biotechnology, cilt 16(7), s. 291-300 https://doi.org/10.1016/S0167-7799(98)01218-9

[11] Pavasant, P., Apiratikul, R., Sungkhum, V., Suthiparinyanont P., Wattanachira, ve S., Marhaba, T.F. 2006. Biosorption of $\mathrm{Cu} 2+, \mathrm{Cd} 2+, \mathrm{Pb} 2+$, and $\mathrm{Zn} 2+$ using dried marine green macroalga Caulerpa lentillifera. Bioresource Technology, cilt 97(18), s. 2321-2329. https://doi.org/10.1016/j.biortech.2005.10.032

[12] Gok, C. ve Aytas, S. 2014. Chapter 16 - Biosorption of Uranium and Thorium by Biopolymers, in The Role of Colloidal Systems in Environmental Protection, M. Fanun, Editor. Elsevier: Amsterdam, s. 363-395. https://doi.org/10.1016/B978-0-444 63283-8.00016-8

[13] McMullan, G., Meehan, C., Conneely, A., Kirby, N., Robinson, T., Nigam, P., Banat, I., Marchant, R., ve Smyth, W. 2001. Microbial decolourisation and degradation of textile dyes. Applied Microbiology and Biotechnology, cilt 56(1-2), s. 81-87.

[14] Abd-El-Kareem, M.S. ve Taha, H.M. 2012. Decolorization of Malachite green and Methylene blue by two microalgal species. International Journal of chemical and environmental engineering, cilt 3(5), s. 297-302.

[15] Ariff, A.B., Mel, M., Hasan, M.A. ve Karim, M.I.A. 1999. The kinetics and mechanism of lead (II) biosorption by powderized Rhizopus oligosporus. World Journal of Microbiology and Biotechnology, cilt 15(2), s. 291-298.

[16] Vieira, R. H. S. F. ve Volesky B. 2010. Biosorption: a solution to pollution? International Microbiology, cilt 3, s. p. 17-24.

[17] Schiewer, S. ve Wong, M.H. 2000. Ionic strength effects in biosorption of metals by marine algae. Chemosphere, cilt 41(1), s. 271-282. https://doi.org/10.1016/S0045-6535(99)00421-X

[18] Malik, D.J., Streat, M., ve Greig, J. 1999. Characterization and Evaluation of Seaweed-Based Sorbents for Treating Toxic Metal-Bearing Solutions. Process Safety and Environmental Protection, cilt 77(4), s. 227-233.

[19] Masoud Riazi, A.R.K., Mohammad Ali Moosavian, Batch and continuous fixed-bed column biosorption of thorium(IV) from aqueous solutions: equilibrium and dynamic modeling. Journal of Radioanalytical and Nuclear Chemistry, 2014. 301(2): p. 493-503.

[20] Khani, M.H., Keshtkar, A.R., Ghannadi, M., ve Pahlavanzadeh, H. 2008. Equilibrium, kinetic and thermodynamic study of the biosorption of uranium onto Cystoseria indica algae. Journal of Hazardous Materials, cilt 150(3), s. 612-618. https://doi.org/10.1016/j.jhazmat.2007.05.010

[21] Vogel, M., Günther, A., Rossberg, A., Li, B., Bernhard, G., ve Raff, J. 2010. Biosorption of U(VI) by the green algae Chlorella vulgaris in dependence of $\mathrm{pH}$ value and cell activity. Science of The Total Environment, cilt 409(2), 38 $39-395$. https://doi.org/10.1016/j.scitotenv.2010.10.011

[22] Wang, J.-S., Hu, X-J., Liu, Y-g., Xi, S-b., ve Bao, Z-I. 2010. Biosorption of uranium (VI) by immobilized Aspergillus fumigatus beads. Journal of Environmental Radioactivity, cilt 101(6): p. 504508. https://doi.org/10.1016/j.jenvrad.2010.03.002.

[23] Picardo, M.C., Melo Ferreira, A.C., ve Augusto da Costa, A. C. 2006. Biosorption of radioactive thorium by Sargassum filipendula. Applied Biochemistry and Biotechnology, cilt 134(3), s. 193-206.

[24] Cecal, A., Humelnicu, D., Rudic, V., Cepoi, L., Ganju, D., ve Cojocari, A. 2012. Uptake of uranyl ions from uranium ores and sludges by means of Spirulina platensis, Porphyridium cruentum and Nostok linckia alga. Bioresource Technology, cilt 118, s. 1923. https://doi.org/10.1016/j.biortech.2012.05.053

[25] Riazi, M., Keshtkar, A.R., ve Moosavian, M.A. 2016. Biosorption of Th(IV) in a fixe d-bed column by Capretreated Cystoseira indica. Journal of Environmental Chemical Engineering, cilt 4(2), s. 1890-1898. https://doi.org/10.1016/j.jece.2016.03.017

[26] Keshtkar, A.R. ve Hassani, M.A. 2014. Biosorption of thorium from aqueous solution by Ca-pretreated 
brown algae Cystoseira indica. Korean Journal of Chemical Engineering, cilt 31(2), s. 289-295.

[27] Langmuir, I. 1918. The adsorption of gases on plane surface of glass, mica and platinum. Journal of the American Chemical Society, cilt 40 (9), s. 1361 1403. DOI: $10.1021 /$ ja02242a004

[28] Freundlich, H. 1906. Over The Adsorption in Solution. Journal of Physical Chemistry, cilt 57, s. 385.

[29] Wang, J. 2002. Biosorption of copper(II) by chemically modified biomass of Saccharomyces cerevisiae. Process Biochemistry, cilt 37(8), s. 847 $850 . \quad$ https://doi.org/10.1016/S00329592(01)00284-9

[30] Sar, P., ve D'Souza, S.F. 2002. Biosorption of thorium (IV) by a Pseudomonas biomass. Biotechnology Letters, cilt 24(3), s. 239-243.

[31] Gavrilescu, M. 2004. Removal of Heavy Metals from the Environment by Biosorption. Engineering in Life Sciences, cilt 4(3), s. 219-232. https://doi.org/10.1002/elsc.200420026.

[32] Abbasizadeh, S., Keshtkar, A.R.. ve Mousavian, M.A. 2013. Preparation of a novel electrospun polyvinyl alcohol/titanium oxide nanofiber adsorbent modified with mercapto groups for uranium(VI) and thorium(IV) removal from aqueous solution. Chemical Engineering Journal, cilt 220, s. 161-171. https://doi.org/10.1016/j.cej.2013.01.029

[33] Tsezos, M. ve Volesky, B. 1981. Biosorption of uranium and thorium. Biotechnology and Bioengineering, cilt $25 \quad$ (3), s. 583-604 https://doi.org/10.1002/bit.260230309

[34] Riazi, M., Keshtkar, A.R., ve Moosavian, M. A. 2014. Batch and continuous fixed-bed column biosorption of thorium(IV) from aqueous solutions: equilibrium and dynamic modeling. Journal of Radioanalytical and Nuclear Chemistry, cilt 301(2), s. 493-503.

[35] Lodeiro P., Barriada, Herrero, J.L., ve Sastre De Vicente, M.E. 2006. The marine macroalga Cystoseira baccata as biosorbent for cadmium (II) and lead (II) removal: kinetic and equilibrium studies. Environmental Pollution, cilt 142, s. 264 273.

[36] Davis, T.A, Volesky, B, ve Mucci, A. 2003. A review of the biochemistry of heavy metal biosorption by brown algae. Water Resource, cilt 37, s. 4311-4330 